\title{
Homocysteine enhances impairment of endothelium-dependent relaxation and guanosine cyclic monophosphate formation in aortae from diabetic rabbits
}

\author{
N. Shukla1 , C. S. Thompson ${ }^{2}$, G. D. Angelini ${ }^{1}$, D. P. Mikhailidis ${ }^{2}$, J. Y. Jeremy ${ }^{1}$ \\ ${ }^{1}$ Bristol Heart Institute, University of Bristol, Bristol, UK \\ ${ }^{2}$ Department of Clinical Biochemistry, Royal Free and University College Medical School, London, UK
}

\begin{abstract}
Aims/hypothesis. Both diabetes mellitus and hyperhomocysteinaemia are risk factors for cardiovascular disease and are associated with impaired endothelial nitric oxide and with excess superoxide formation. To explore potential vasculopathic interactions between these risk factors, the effect of homocysteine on endothelium-dependent relaxation and cyclic GMP formation was investigated in aortae from diabetic rabbits.

Methods. Rabbits were rendered diabetic by intravenous injection of alloxan. Six months later, the aortae were excised, cut into rings and mounted in an organ bath for isometric measurement of acetylcholineevoked relaxation in rings pre-contracted with phenylephrine. Cyclic GMP formation by aortic rings after stimulation with acetylcholine, calcium ionophore A23187 and sodium nitroprusside was assessed using radioimmunoassay. The effect of homocysteine on these parameters was then studied.
\end{abstract}

Results. Ach-evoked relaxation and cyclic GMP formation induced with acetylcholine and calcium ionophore A23187 were impaired in aortae from diabetic rabbits compared with the control rabbits, effects that were reversed with superoxide dimutase (SOD) and augmented by $10-100 \mu \mathrm{mol} / \mathrm{l}$ homocysteine, an effect again reversed by SOD.

Conclusion/interpretation. These data show that the bioavailability of nitric oxide is reduced in aortae from diabetic rabbits due to excess production of superoxide, an effect augmented by homocysteine. These results indicate that patients with diabetes mellitus could be susceptible to homocysteine-mediated angiopathy at lower concentrations than those that promote vasculopathy in non-diabetic patients. [Diabetologia (2002) 45:1325-1331]

Keywords Diabetes, homocysteine, superoxide, nitric oxide, angiopathy.
Both diabetes mellitus and hyperhomocysteinaemia (HH) are risk factors for cardiovascular disease (CVD) $[1,2]$ and are associated with impaired endothelial nitric oxide and with excess superoxide $\left(\mathrm{O}_{2}^{-}\right)$

Received: 22 February 2002 / Revised: 10 April 2002

Published online: 10 July 2002

C) Springer-Verlag 2002

Corresponding author: Dr. J. Y. Jeremy, Bristol Royal Infirmary, University of Bristol, Bristol BS2 8HW, UK, E-mail: j.y.jeremy@bris.ac.uk

Abbreviations: $\mathrm{HH}$, Hyperhomocysteinaemia; $\mathrm{O}_{2}$, superoxide; SOD, superoxide dismutase; VSMC, vascular smooth muscle cell; Hcy, homocysteine; ONOO, peroxynitrite formation $[3,4,5,6,7,8,9,10,11]$. Clinically, there are now a number of studies indicating that homocysteine (Hcy) potentiates CVD in diabetic patients [2]. The underlying mechanisms that assess the vasculopathic impact of $\mathrm{HH}$ and diabetes mellitus, both alone or interactively, are not completely understood. It is now established, however, that Hcy promotes oxidative stress, including superoxide formation which could be mediated by Hcy-mediated vasculopathy $[3,4,5]$. Superoxide elicits a number of pro-atherogenic effects including endothelial dysfunction, oxidation of lipids and the promotion of vascular smooth muscle cell (VSMC) proliferation [5]. Superoxide also reacts readily with nitric oxide to produce peroxynitrite 
(ONOO), thereby reducing the bioavailability of nitric oxide [12]. In turn, impaired endothelium nitric oxide dependent relaxation of arteries in patients with $\mathrm{HH}$ has been reported [13, 14]. Diminished NO formation by Hcy in laboratory animals and in vitro systems is well documented $[3,4,5,15,16]$. Since reduced nitric oxide formation is associated with vascular disease $[5$, 6], the pathogenic impact of Hcy could be mediated, in part, through an $\mathrm{O}_{2}{ }^{-}$-mediated reduction of $\mathrm{NO}$ bioavailability $[4,5]$. Similarly, diabetes mellitus is also associated with impaired endothelial function and reduced nitric oxide formation as well as increased $\mathrm{O}_{2}-$ generation by the vasculature $[7,8,9,10,11]$.

It is reasonable to propose, therefore, that the potentiation of diabetic angiopathy by Hcy could be mediated by a common denominator mechanism: i.e. the impairment of nitric oxide formation by the overproduction of $\mathrm{O}_{2}^{-}$. In order to test this proposal we studied the effect of exogenous Hcy on endothelium-dependent relaxation and cyclic GMP formation (index of endothelial nitric oxide bioactivity) in aortae from hyperglycaemic, non-ketotic, diabetic rabbits.

\section{Materials and methods}

Drugs and materials. Acetylcholine, alloxan, calcium ionophore A23187, catalase, DL-homocysteine, indomethacin, isobutylmethylxanthine, phenylephrine, sodium nitroprusside, CuZn superoxide dismutase and all buffer components were purchased from Sigma Chemical (Poole, Dorset, UK). Dual range $\left[{ }^{125} \mathrm{I}\right]$ cGMP kits were purchased from Amersham Radiochemicals (Amersham, UK). All animals received humane care according to the Home Office Animal Care regulations (UK), for which ethics committee approval and licensing had been obtained.

Induction of diabetes. Male New Zealand white rabbits $(3 \mathrm{~kg})$ matched for age were injected intravenously with alloxan (Sigma Chemical, Poole Dorset) via the lateral ear vein at a stat dose of $65 \mathrm{mg} / \mathrm{kg}$ [17]. The diabetic rabbits were fed ad libitum with SDS standard rabbit chow (SDS, Whitham, UK) and allowed free access to water. Blood was sampled at monthly intervals for serum urea and electrolytes, cholesterol, triglycerides and glucose by the routine section of the Department of Clinical Chemistry, Royal Free Hospital, London. Urine was also monitored over the duration of diabetes for glucose, ketone bodies and proteins with Multistix (Ames Division, Miles Laboratories, Stoke Poges, Buckinghamshire, UK).

Organ bath studies. The rabbits were killed by cervical dislocation 6 months after the induction of diabetes mellitus and the aortae were rapidly excised and placed in cold oxygenated Kreb's solution (KRB). Adventitial tissue was removed and the aortae were cut into $2 \mathrm{~mm}$ rings and mounted vertically in $15 \mathrm{ml}$ capacity organ attached to Grass FTO3 force displacement transducer and data recorded on disc using MacLab. In each experiment, four rings were set up simultaneously. An initial tension of $2 \mathrm{~g}$ was applied to the suspended tissue strips, which were then equilibrated for $30 \mathrm{~min}$, after which time tension was reset. The experiment commenced after a further equilibration time of $30 \mathrm{~min}$. DL-Hcy $( \pm$ SOD) were then added to the organ bath chamber at different concentrations and left to equilibrate for $30 \mathrm{~min}$. Contraction was then elicited with phenylephrine (PE; $1-3 \mu \mathrm{mol} / 1)$, the concentration of PE being adjusted to give the same level of tension $(2 \mathrm{~g})$ in all rings. The rings were then relaxed with a cumulative concentrations of the endothelium vasodilator, acetylcholine (Ach; 0.01-10 $\mu \mathrm{mol} / \mathrm{l}$ ) or the endothelium-independent vasodilator, sodium nitroprusside (SNP; 0.001-10 $\mu \mathrm{mol} / \mathrm{l}$ ).

Cyclic GMP formation. Aortae from the control rabbits and diabetic rabbits were cut into $2 \mathrm{~mm}$ segments as described. Rings were then placed in polypropylene tubes containing $250 \mu \mathrm{mol} / 1$ of the phosphodiesterase (PDE) inhibitor, isobutylmethylxanthine (IBMX) in KRB and various concentrations of Hcy and/or CuZnSOD or catalase. After $30 \mathrm{~min}$ incubation at $37^{\circ} \mathrm{C}$, cGMP formation was stimulated with: (i) acetylcholine (generates nitric oxide through receptor mediated increase in $\mathrm{Ca}^{2+}$ and NOS activation), (ii) calcium ionophore A23187 (activates nitric oxide synthase through an increase of cytosolic $\mathrm{Ca}^{2+}$ ) and (iii) sodium nitroprusside (SNP: activates guanylyl cyclase directly). Tubes were incubated for a further $20 \mathrm{~min}$ at $37^{\circ} \mathrm{C}$. Reactions were stopped by the addition of $1 \mathrm{~mol} / \mathrm{l}$ perchloric acid and the tissues sonicated $(3 \times 30 \mathrm{~s}$; Soniprep, MSE, Bucks, UK). After centrifugation at $1000 \mathrm{~g}$ for $15 \mathrm{~min}$, supernatants were taken and neutralised with $1 \mathrm{~mol} / 1 \mathrm{~K}_{3} \mathrm{PO}_{4}$. Aliquots were then taken and acetylated with triethylamine/acetic anhydride $(1 / 2, v / v)$ and diluted with PBS (pH 7.4). To these cGMP standards (0-256 fmoles) $200 \mu$ diluted antisera against cGMP antisera containing $\left[{ }^{125} \mathrm{I}\right]$ cGMP was added. After overnight incubation at $4^{\circ} \mathrm{C}$, antisera against rabbit globulins in phosphate buffer was added to each tube and incubated for $15 \mathrm{~min}$ on melting ice. Tubes were then centrifuged at $2500 \mathrm{rpm}$ for 10 min. Supernatants were decanted into vials and scintillation fluid added and counted in a gamma particle counter. Standard curves were compiled and unknown values calculated.

Data analysis and statistics. Comparisons of weights, plasma glucose and plasma lipids between the 6-month diabetic groups and the age-matched controls were carried out using the Wilcoxon test (paired values). For the cGMP measurements data are related to $\mathrm{mg}$ tissue per min (wet weight). Each data point is expressed as mean \pm standard error of the mean (SEM). Responses of isolated aortic rings to Ach and SNP are expressed as the percentage of relaxation of PE-induced contraction, with maximal relaxation being arbitrarily set at basal tension (i.e. 100\%). Organ bath and cGMP data were analysed with a paired Student's $t$ test for the multiple comparison using ANOVA subjected to a Bonforroni adjustment. Statistical significance was accepted when the $p$ value was less than 0.05 .

\section{Results}

Animal weights, serum glucose and cholesterol concentrations. The starting weights in both the control and diabetic rabbit groups were similar (control: median, $3.0 \mathrm{~kg}$; range, 2.7-3.5, $n=6$; diabetic: median, 3.1 ; range, $2.8-3.6, n=6)$. The diabetic rabbits were $(p<0.03)$ lighter than the control group (control: median, $4.1 \mathrm{~kg}$; range, 3.5-4.35, $n=6$; diabetic: median, 3.6; range, 3.0-3.9, $n=6$ ). Serum glucose concentrations (non-fasting) were increased $(p<0.009)$ in the 6month diabetic group $(32.2 ; 18.3-41.1, n=6)$ compared with the control group (median, $6.4 \mathrm{mmol} / \mathrm{l}$; range, 6.1-7.5 mmol/l, $n=6$ ). Serum cholesterol con- 
Table 1. Comparison of phenylephrine-induced contractions ( $\%$ maximal) in aortae from diabetic rabbits and age-matched control rabbits (6 months duration). Data $=$ mean \pm SEM, $n=6$

Concentration of phenylephrine $(\mathrm{mol} / \mathrm{l})$

\begin{tabular}{llllll}
\hline & $1 \times 10^{-8}$ & $3 \times 10^{-8}$ & $1 \times 10^{-7}$ & $3 \times 10^{-7}$ & $1 \times 10^{-6}$ \\
\hline Control rabbits & $5 \pm 0.5$ & $15 \pm 1.2$ & $43 \pm 3.6$ & $64 \pm 5.2$ & $83 \pm 8.3$ \\
Diabetic rabbits & $6 \pm 0.4$ & $16 \pm 1.2$ & $45 \pm 4.3$ & $67 \pm 5.4$ & $88 \pm 6.2$ \\
\hline
\end{tabular}

Table 2. Comparison of sodium nitroprusside (SNP)-induced relaxation (\% maximal) in aortae from diabetic (6 months duration) and age-matched control rabbits. Data $=$ mean \pm SEM, $n=6$

Concentration of SNP (mol/l)

\begin{tabular}{|c|c|c|c|c|c|c|}
\hline & $1 \times 10^{-8}$ & $3 \times 10^{-8}$ & $1 \times 10^{-7}$ & $3 \times 10^{-7}$ & $1 \times 10^{-6}$ & $3 \times 10^{-6}$ \\
\hline Control rabbits & $2 \pm 0.2$ & $3 \pm 0.3$ & $12 \pm 1.3$ & $50 \pm 5.9$ & $85 \pm 8.8$ & $99 \pm 7.4$ \\
\hline Diabetic rabbits & $3 \pm 0.2$ & $2 \pm 0.1$ & $14 \pm 1.4$ & $53 \pm 5.3$ & $88 \pm 8.1$ & $99 \pm 6.9$ \\
\hline
\end{tabular}

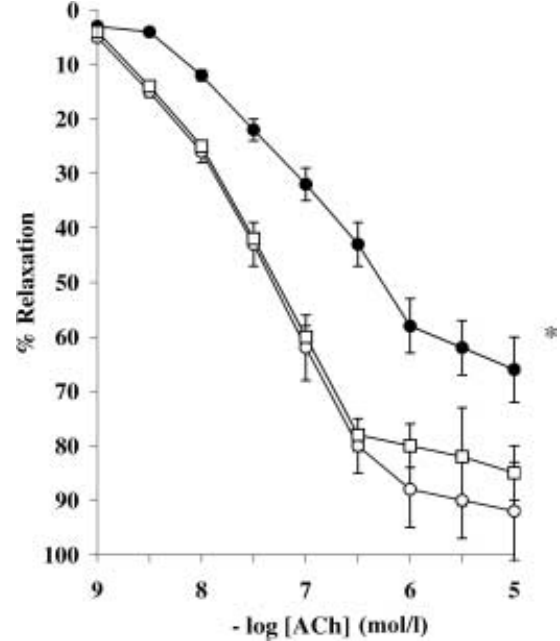

Fig. 1. Acetylcholine-evoked relaxation of aortic rings from diabetic (solid circles) rabbits and control (open circles) rabbits, and diabetic $+300 \mathrm{U} / \mathrm{ml}$ SOD (open squares) 6 months after the induction of diabetes. N.B. $300 \mathrm{U} / \mathrm{ml} \mathrm{SOD} \mathrm{had} \mathrm{no} \mathrm{effect}$ on relaxation in aortae from control animals. Each point $=$ mean \pm SEM, $n=6$ animals. ${ }^{*} p<0.001$ control vs diabetic

centrations (non-fasting) were not significantly different between the 6-month control group (median = $1.2 \mathrm{mmol} / \mathrm{l}$; range, $0.6-2.3 ; n=6)$ and the diabetic group $($ median $=0.9 \mathrm{mmol} / 1$; range, $0.5-1.3 ; n=6$ ). Serum triglycerides were not different between the control and diabetic groups [17].

Organ bath studies and cGMP concentrations. PEinduced contractions were not different in aortae from the diabetic rabbits compared with the control rabbits (Table 1). However, Ach-stimulated relaxation was impaired in aortae from diabetic rabbits compared to the control rabbits (Fig. 1). The impairment of Achstimulated relaxation in diabetic animals was reversed

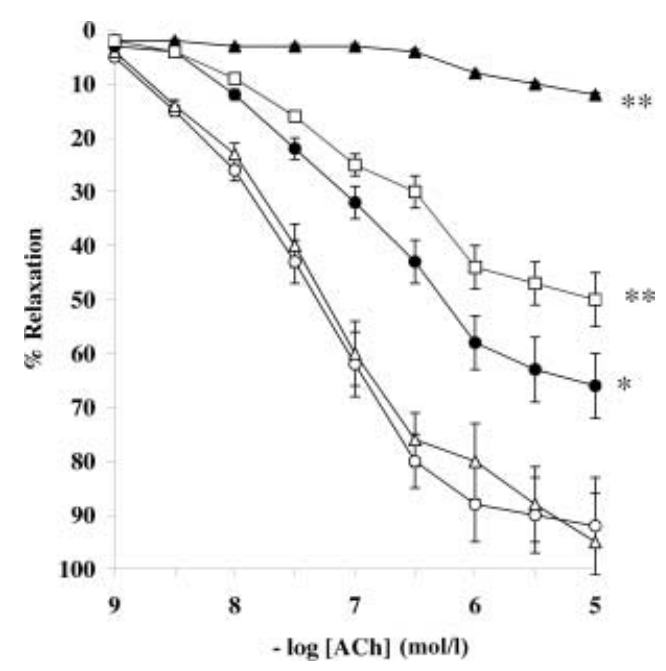

Fig. 2. Effect of homocysteine (Hcy) on acetylcholine-evoked relaxation of aortic rings from diabetic (6 months duration) and control rabbits. Each point $=$ mean \pm SEM, $n=6$. $* p<0.001$ control vs diabetic; $* * p<0.01$ diabetic control vs homocysteine additions. Diabetic without additions (solid circles); control without additions (open circles); diabetic plus $10 \mu \mathrm{mol} / \mathrm{l} \mathrm{Hcy}$ (open squares); diabetic plus $100 \mu \mathrm{mol} / \mathrm{l} \mathrm{Hcy} \mathrm{(solid} \mathrm{triangles);}$ diabetic $100 \mu \mathrm{mol} / \mathrm{l} \mathrm{Hcy}+300 \mathrm{U} / \mathrm{ml}$ SOD (open triangles)

with SOD (300 U/ml) in aortae from diabetic rabbits but SOD had no effect on the control rabbits (Fig. 1). In contrast, there were no differences in sodium nitroprusside (SNP)-stimulated relaxation of aortae from diabetic rabbits compared to the control rabbits (Table 2).

Following pre-incubation for $30 \mathrm{~min}$ with Hcy $(10 \mu \mathrm{mol} / \mathrm{l}$ and $100 \mu \mathrm{mol} / \mathrm{l})$, there was a further inhibition of Ach-stimulated relaxation in aortae from diabetic rabbits, an effect reversed with $300 \mathrm{U} / \mathrm{ml}$ SOD (Fig. 2). In contrast, incubation for $30 \mathrm{~min}$ with Hcy $(10 \mu \mathrm{mol} / \mathrm{l}$ and $100 \mu \mathrm{mol} / \mathrm{l})$ had no effect on Achstimulated relaxation in aortae from the control rab- 


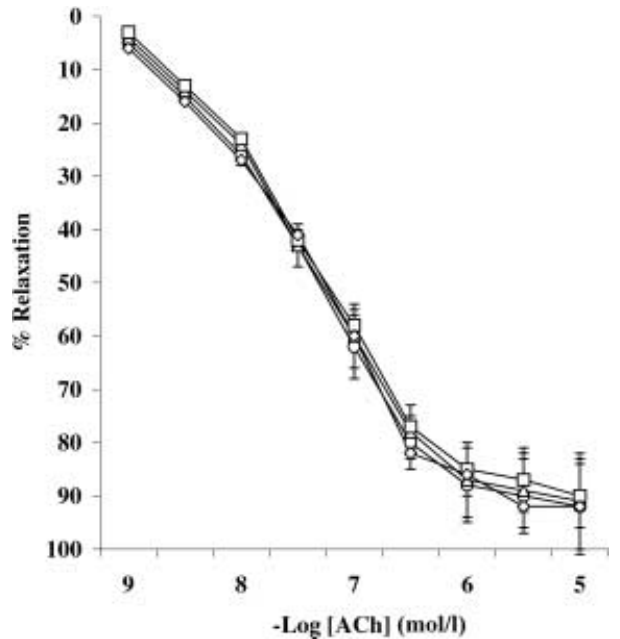

Fig. 3 Effect of homocysteine (Hcy) on acetylcholine-evoked relaxation of aortic rings from control (non-diabetic) rabbits. Control without additions (open circles); plus $10 \mu \mathrm{mol} / \mathrm{l} \mathrm{Hcy}$ (open squares); plus $100 \mu \mathrm{mol} / 1 \mathrm{Hcy}$ (open triangles); $100 \mu \mathrm{M}$ Hcy $+300 \mathrm{U} / \mathrm{ml} \mathrm{SOD.} \mathrm{Each} \mathrm{point}=$ mean $\pm \mathrm{SEM}, n=6$

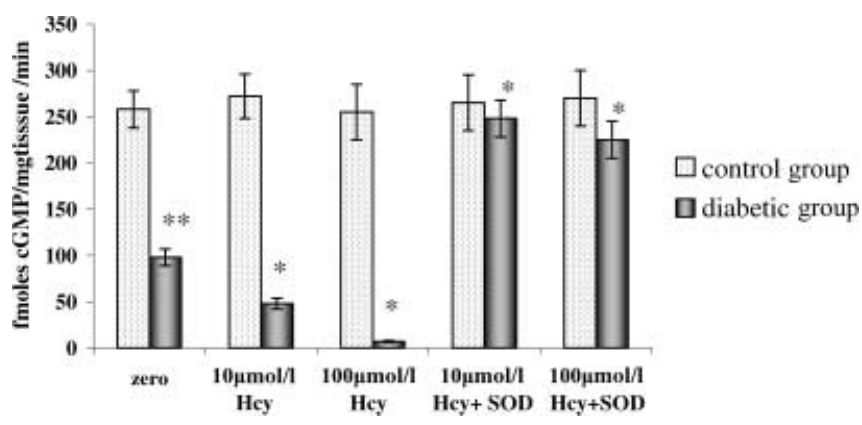

Fig. 4 Effect of homocysteine (Hcy) (with and without SOD) on acetylcholine-evoked A23187-evoked cGMP formation by aortic rings from diabetic rabbits (6 months duration) and control rabbits. Each bar $=$ mean \pm SEM, $n=6$. $* * p<0.001$ diabetic vs control rabbits $* p<0.01$ diabetic vs homocysteine additions

bits (Fig. 3). Furthermore, Hcy (at $10 \mu \mathrm{mol} / \mathrm{l}$ and $100 \mu \mathrm{mol} / \mathrm{l}$ ), had no effect on SNP (nitric oxide donor)-mediated relaxation (Table 3 ).

Both Ach-stimulated and A23187-stimulated cGMP formation was impaired in aortae from diabetic

Table 3 The effect of 30-min preincubation of homocysteine (Hcy) at $10 \mu \mathrm{mol} / \mathrm{l}(+10)$ and $100 \mu \mathrm{mol} / \mathrm{l}(+100)$ on sodium nitroprusside (SNP)-evoked relaxation (\% maximal) in aortae

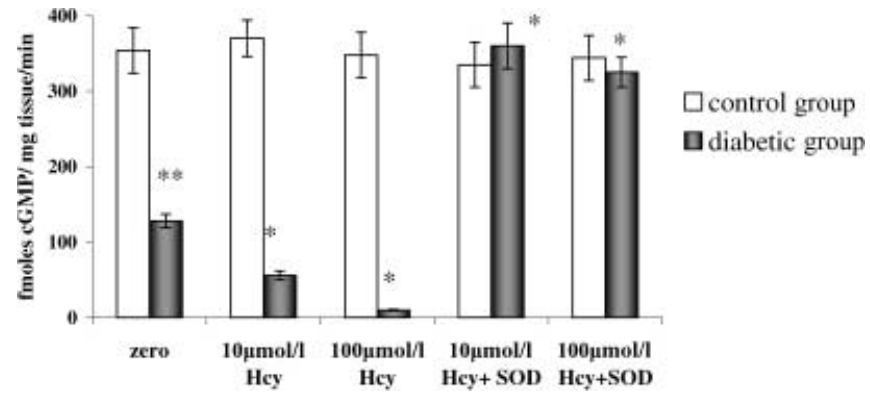

Fig. 5 Effect of homocysteine (Hcy) (with and without $300 \mathrm{U} / \mathrm{ml}$ SOD) on calcium ionophore A23187-evoked cGMP formation by aortic rings from diabetic rabbits (6 months duration) and control rabbits. Each $b a r=$ means \pm SEM, $n=6$. $* * p<0.001$ diabetic vs control rabbits $* p<0.01$ diabetic vs homocysteine additions

Table 4 Effect of homocysteine (Hcy) on sodium nitroprusside [SNP $(1 \mu \mathrm{mol} / \mathrm{l})]$-stimulated cGMP formation (fmoles.mg tissue ${ }^{-1} \cdot \mathrm{min}^{-1}$ ) [means $\pm \mathrm{SEM}, n=6$ ] in aortae from diabetic and control rabbits

\begin{tabular}{llll}
\hline & Zero & $10 \mu \mathrm{mol} / \mathrm{l} \mathrm{Hcy}$ & $100 \mu \mathrm{mol} / 1 \mathrm{Hcy}$ \\
\hline Control rabbits & $880 \pm 76$ & $870 \pm 83$ & $890 \pm 67$ \\
Diabetic rabbits & $875 \pm 56$ & $860 \pm 56$ & $856 \pm 54$ \\
\hline
\end{tabular}

rabbits compared to control rabbits (Figs. 4 and 5). The similarity of the impairment of cGMP formation to that of relaxation in response to Ach consolidates that the reduction of relaxation in diabetic aortae is due to an impairment of the nitric oxide-cGMP axis rather than other pathways (e.g. EDHF or $\mathrm{PGI}_{2}$ ). In contrast, there were no differences in sodium nitroprusside (SNP)-stimulated cGMP formation by aortae from diabetic rabbits compared to control rabbits (Table 4). Following pre-incubation for $30 \mathrm{~min}$ with Hcy $(10 \mu \mathrm{mol} / 1$ and $100 \mu \mathrm{mol} / \mathrm{l})$, there was further inhibition of Ach-stimulated and A23187-stimulated cGMP formation in aortae from diabetic rabbits, an effect reversed with $300 \mathrm{U} / \mathrm{ml} \mathrm{SOD}$, but no significant changes in the control rabbits (Figs. 4, 5).

from control (C) or diabetic rabbits (D) of 6 months duration. Each point $=$ mean \pm SEM, $n=6$

Concentration of SNP (mol/l)

\begin{tabular}{|c|c|c|c|c|c|c|}
\hline & $1 \times 10^{-8}$ & $3 \times 10^{-8}$ & $1 \times 10^{-7}$ & $3 \times 10^{-7}$ & $1 \times 10^{-6}$ & $3 \times 10^{-6}$ \\
\hline C+zero & $2 \pm 0.2$ & $3 \pm 0.3$ & $12 \pm 1.3$ & $50 \pm 5$ & $83 \pm 8$ & $99 \pm 7$ \\
\hline C+10 Нcy & $2 \pm 0.2$ & $4 \pm 0.1$ & $11 \pm 1.8$ & $48 \pm 4$ & $84 \pm 5$ & $93 \pm 6$ \\
\hline D+zero & $2 \pm 0.2$ & $3 \pm 0.3$ & $12 \pm 1.3$ & $49 \pm 5$ & $85 \pm 8$ & $99 \pm 7$ \\
\hline $\mathrm{D}+10 \mathrm{HCy}$ & $3 \pm 0.2$ & $2 \pm 0.1$ & $14 \pm 1.4$ & $53 \pm 5$ & $88 \pm 8$ & $98 \pm 6$ \\
\hline $\mathrm{D}+100 \mathrm{HCy}$ & $3 \pm 0.2$ & $2 \pm 0.1$ & $14 \pm 1.4$ & $53 \pm 5$ & $88 \pm 8$ & $94 \pm 6$ \\
\hline
\end{tabular}




\section{Discussion}

The similarity of the impairment of cGMP formation to that of relaxation in response to Ach consolidates that the reduction of relaxation in diabetic aortae is caused by an impairment of the nitric oxide-cGMP axis rather than other pathways (e.g. EDHF or $\mathrm{PGI}_{2}$ ). Nitric oxide release following endothelial nitric oxide synthase (eNOS) activation is mediated by an increase in cytosolic calcium, which in the case of Ach is mediated by a receptor-linked mechanism and in the case of calcium ionophore A23187 through nonspecific calcium influx [6]. Since SNP-stimulated relaxation and cGMP formation were not affected (indicating no effect on guanylyl cyclase), the impairment of Ach-mediated relaxation, as well as Ach-and A23187-stimulated cGMP formation in the aortae from diabetic animals, indicates that the impairment is not due to an inhibition of Ach receptors or associated signal transduction systems (e.g. G proteins, phospholipase $\mathrm{C}$ and inositol trisphosphate formation) but to a reduction in nitric oxide bioavailability. In contrast, there were no differences in sodium nitroprusside (SNP)-stimulated cGMP formation by aortae from diabetic rabbits compared to control rabbits. Taken together, these data indicate that diabetes mellitus reduces NOS activity and/or the bioavailability of nitric oxide but does not reduce guanylyl cyclase activity in aortae from diabetic rabbits. The impairment of both Ach-stimulated and A23187-stimulated cGMP formation was reversed by SOD, indicating that this impairment was caused by increased superoxide formation. These data are in keeping with previous reports of impaired endothelium dependent relaxation and nitric oxide formation in arteries from diabetic animals $[8,9,17]$.

The reversal of the reduced relaxation and cGMP formation in response to Ach and A23187 by SOD in aortae from diabetic rabbits also indicates that this impairment is due to excess $\mathrm{O}_{2}^{-}$. Since $\mathrm{O}_{2}^{-}$reacts with nitric oxide to form peroxynitrite (ONOO), effectively reducing local nitric oxide availability $[5,6,12]$, this explains the present effects of diabetes mellitus on endothelium-dependent relaxation. Although ONOO itself can promote relaxation, it is 1000 times less potent than nitric oxide [19]. ONOO also rapidly breaks down to produce other toxic free radicals [12]. Several studies have now shown a reduction of nitric oxide and an increase in $\mathrm{O}_{2}{ }^{-}$formation by the vasculature of diabetic laboratory animals $[8,9,20,21,22,23]$. In support of these observations, the adenoviral gene transfer of both eNOS and SOD have been shown to reverse the reduction of endothelium-dependent relaxation in the diabetic rabbit $[24,25]$.

The over-production of $\mathrm{O}_{2}^{-}$in diabetic animals has been ascribed, in part, to a reduction in endogenous vascular SOD activity [26]. In humans, Type I (insulin-dependent) diabetes mellitus is also associated with reduced SOD activity due to increased glycation of the enzyme [27]. The excess production of $\mathrm{O}_{2}{ }^{-}$by the vasculature of diabetic animals has also been attributed to the over-expression of endogenous $\mathrm{O}_{2}^{-}$ generating enzymes, including NADPH oxidase, xanthine oxidase, cyclooxgenase and lipoxygenase as well as the auto-oxidation of glucose and mitochondrial respiration $[8,7,20]$.

In our study, pre-incubation with $10 \mu \mathrm{mol} / \mathrm{l}$ and $100 \mu \mathrm{mol} / \mathrm{l}$ Hcy for $30 \mathrm{~min}$ caused a further impairment of both Ach-evoked relaxation and cGMP formation in aortae from diabetic rabbits but had no effect in aortae from age-matched control animals. This marked potentiating effect was also reversed by SOD, indicating that Hcy augments an already established increase in $\mathrm{O}_{2}{ }^{-}$formation by vascular tissue from diabetic animals, possibly by acting at a common denominator site. In previous studies in which the effect of Hcy on endothelium-dependent relaxation was investigated, exposure to $1 \mathrm{mmol} / \mathrm{l} \mathrm{Hcy}$ for $3 \mathrm{~h}$ was required to elicit an inhibitory effect in isolated rat aortic rings [18]. Since Hcy autoxidises to form $\mathrm{O}_{2}{ }^{-}$[3] it is reasonable to suggest that arterial tissue from diabetic animals could accelerate the auto-oxidation of Hcy. Thus, the inhibitory effects of Hcy obtained at $10 \mu \mathrm{mol} / \mathrm{l}$ and $100 \mu \mathrm{mol} / \mathrm{l}$ constitutes a striking reduction in the inhibitory capacity of the amino acid on nitric oxide formation and actions (i.e. cGMP formation). As discussed above, there are other junctures at which Hcy could be exerting this effect: an increase in pro-oxidant enzyme activity (e.g. NADPH oxidase), an inhibition of antioxidant systems (e.g. SOD) or both.

Clinically, the relation between diabetes mellitus, Hcy and angiopathy is not clear. A number of studies have indicated a potentiating association between diabetes mellitus, Hcy and CVD [2, 28, 29, 30] and increased plasma Hcy concentrations in patients with Type I diabetes mellitus [31, 32, 33, 34]. In Type II (non-insulin-dependent) diabetic patients, fasting and post-methionine load Hcy concentrations are also above normal $[35,36]$. There are other reports, however, that Hcy concentrations are not increased in diabetes mellitus and that homocysteinaemia is not correlated with angiopathy in diabetic patients $[2,35,38$, 39]. Our studies indicate that increased plasma concentrations of Hcy might not necessarily be a prerequisite for the promotion of angiopathy in diabetes mellitus, which in turn could explain the lack of correlation between increased Hcy and angiopathy in diabetes mellitus found in some studies.

Although the concentration at which Hcy was inhibitory in this study $(10 \mu \mathrm{mol} / \mathrm{l})$ "normophysiological", in vivo, circulating Hcy exists in several forms. Approximately $80 \%$ of Hcy is bound to proteins in blood [40, 41]. The remaining unbound Hcy can form a dimer with itself, can exist as a homocysteine-cysteine complex as well as in a reduced or oxidised form 
[40, 41], attributes that could be central to its pathological influence in diabetes mellitus. An examination of all these different forms of Hcy was beyond the scope of our study.

In conclusion, our study shows that concentrations of Hcy that have no effect on aorta from normal rabbits markedly impair endothelium-dependent relaxation and nitric oxide-dependent cGMP formation in aortae from diabetic rabbits. Since these effects were reversed by SOD, we conclude that the effect is mediated by an augmentation of $\mathrm{O}_{2}-$ formation perhaps due to reduced SOD activity, increase pro-oxidant enzymes or an acceleration of Hcy oxidation. This, in turn, indicates that concentrations of Hcy that have no effect in normal tissue can exert a deleterious impact on nitric oxide-dependent systems when diabetes mellitus is present. For intervention, supplementation of the diet with folate or the $\mathrm{B}_{6}$ and $\mathrm{B}_{12}$ vitamins have been used to reduce plasma Hcy [1, 2, 3]. Given the evidence that diabetes mellitus and Hcy could interact to promote angiopathy through the generation of superoxide $[4,5]$ the administration of SOD mimetics or antioxidants, possibly as adjuvants to vitamin supplements, could be an alternative strategy in this particular clinical scenario.

\section{References}

1. Robinson K (2000) Homocysteine, B vitamins and risk of cardiovascular disease. Heart 83:127-130

2. Audelin MC, Genest J Jr (2001) Homocysteine and cardiovascular disease in diabetes mellitus. Atherosclerosis 159:497-511

3. Loscalzo J (1996) The oxidant stress of hyperhomocysteinemia. J Clin Invest 98:5-7

4. Emsley AM, Plane F, Jackson CL, Miller AL, Jeremy JY (1998) Oxidant stress, nitric oxide and transition metals in homocysteinaemic angiopathy: novel mechanisms. Vasc Dis 1:66-72

5. Fonseca VA, Stone A, Munshi M et al. (1997) Oxidative stress in diabetic macrovascular disease: does homocysteine play a role? South Med J 90:903-906

6. Jeremy JY, Rowe D, Emsley AM, Newby AC (1999) Nitric oxide and vascular smooth muscle cell proliferation. Cardiovasc Res 43:658-665

7. Tesfamariam B, Cohen RA (1996) Free radicals mediate endothelial cell dysfunction caused by elevated glucose. Am J Physiol 263:H321-H326

8. Cooper ME, Bonnett F, Oldfield M, Jandeliet-Dahm K (2001) Mechanisms of diabetic vasculopathy: an overview. Am J Hypertens 14:475-486

9. Pieper GM, Gross GJ (1988) Oxygen free radicals abolish endothelium-dependent relaxation in diabetic rat aortae. Am J Physiol 263:H825-H830

10. Kojda G, Harrison D (1999) Interaction between NO and reactive oxygen species: pathological importance in atherosclerosis, hypertension, diabetes and heart failure. Cardiovasc Res 43:562-571

11. Pieper GM (2000) Hyperglycaemia and diabetes induced vascular dysfunction: role of oxidative stress. In: Oxidative stress and vascular disease. Keaney JF (ed) Kluwer Academic Press, Norwell, Mass. USA, pp 305-322
12. Darley-Usmar V, White R (1997) Disruption of vascular signalling by the reaction of nitric oxide with superoxide: implication for cardiovascular disease. Exp Physiol 82:305-316

13. Van den Berg M, Boers GH, Franken DG et al. (1995) Hyperhomocysteinaemia and endothelial dysfunction in young patients with occlusive peripheral arterial disease. Eur J Clin Invest 25:176-181

14. Tawakol A, Omland T, Gerhard M, Wu JY, Creager MA (1997) Hyperhomocysteinaemia is associated with impaired endothelium-dependent vasodilation in humans. Circulation 95:1119-1121

15. Jia L, Furchgott RF (1997) Blockade of nitric oxide mediated relaxation of rabbit aorta by cysteine and homocysteine. Acta Pharmacol Sin 18:11-20

16. Lang D, Kredan MB, Moat SJ et al. (2000) Homocysteineinduced inhibition of endothelium-dependent relaxation in rabbit aorta. Role for superoxide. Arterioscler Thromb Vasc Biol 20:422-427

17. Thompson C, Khan M, Mikhailidis D, Morgan RJ, Angelini GD, Jeremy JY (2001) Effect of sildenafil (Viagra ${ }^{\mathrm{TM}}$ ) on relaxation of the corpus cavernosum of the diabetic rabbit. Eur J Pharmacol 425:57-64

18. Emsley AM, Jeremy JY, Gomes GN, Angelini GD, Plane F (1999) Investigation of the inhibitory effects of homocysteine and copper on nitric oxide-mediated relaxation of rat isolated aorta. Br J Pharmacol 126:1034-1040

19. Liu S, Beckman JS, Ku DD (1994) Peroxynitrite, a product of superoxide and nitric oxide produces coronary vasorelaxation in dogs. J Pharmacol Exp Ther 268:1114-1121

20. Pieper GM, Siebenheich W (1997) Diabetes-induced endothelial dysfunction is prevented by long-term treatment with the modified iron chelator, hydroxyethyl starch conjugated-deferoxamine. J Cardiovasc Pharmacol 30:734-738

21. Ammar RF, Gutterman DD, Brooks LA, Dellsperger KC (2000) Free radicals mediate endothelial dysfunction of coronary aerterioles in diabetes. Cardiovasc Res 47:595-601

22. DeVries AS, Verbeuren TJ, Van De Voorde J, Lameire NH, Vanhoutte PM (2000) Endothelial dysfunction in diabetes. Br J Pharmacol 130:963-974

23. Oyama Y, Kawasaki H, Hattori Y, Kanno M (1986) Attenuation of endothelium-dependent relaxation in aorta from diabetic rats. Eur J Pharmacol 131:75-78

24. Zanetti M, Sato J, Katusic ZS, O'Brien TO (2000) Gene transfer of endothelial nitric oxide synthase alters endothelium-dependent relaxation in aortas from diabetic rabbits. Diabetologia 43:340-347

25. Zanetti M, Sato J, Katusic ZS, O'Brien TO (2001) Gene transfer of superoxide dismutase isoforms reverses endothelial dysfunction in diabetic rabbit aorta. Am J Physiol 280:H2516-H2523

26. Kamata K, Kobayashi T (1996) Changes in superoxide dismutase mRNA expression by streptozotocin-induced diabetes. Br J Pharmacol 119:583-589

27. Wolff SP, Bascal ZA, Hunt JV (1989) Autoxidative glycosylation: free radicals and glycation theory. In: Baynes JW, Monnier VM (eds) The Maillard Reaction in aging, diabetes and nutrition. Liss, New York, pp 259-275

28. Hoogeveen EK, Kostense PJ, Beks PJ et al. (1998) Hyperhomocysteinaemia is associated with an increased risk of cardiovascular disease, especially in non-insulin dependent diabetes mellitus. Arterioscler Thromb Vasc Biol 18:13331338

29. Hoogeveen EK, Kostense PJ, Jakobs C et al. (2000) Hyperhomocysteinemia increases risk of death, especially in type 2 diabetes: 5-year follow-up of the Hoorn Study. Circulation 101:1506-1511 
30. Okada E, Oida K, Tada H et al. (1999) Hyperhomocysteinaemia is a risk factor for coronary arteriosclerosis in Japanese patients with type II diabetes. Diabetes Care 22:484-490

31. Munshi MN, Stone A, Fink L, Fonseca V (1996) Hyperhomocysteinaemia following a methionine load in patients with non-insulin dependent diabetes mellitus and macrovascular disease. Metabolism 45:133-135

32. Araki A, Sako Y, Ito H (1993) Plasma homocysteine concentrations in Japanese patients with non-insulin dependent diabetes mellitus: effect of parenteral methylcobalamin treatment. Atherosclerosis 103:149-157

33. Neugebaeuer S, Baba T, Kurokawa K, Watanabe T (1997) Defective homocysteine metabolism as a risk factor for diabetic retinopathy. Lancet 349:473-474

34. Hultberg B, Agardh CD, Agardh E, Lovestam-Adrian M (1997) Poor metabolic control, early age at onset, and marginal folate deficiency are associated with increasing levels of plasma homocysteine in insulin-dependent diabetes mellitus. A five-year follow-up study. Scand J Clin Lab Invest 57:595-600

35. Smulders YM, Rakic M, Slaats EH et al. (1999) Fasting and post-methionine homocysteine levels in NIDDM. Determinants and correlations with retinopathy, albuminuria, and cardiovascular disease. Diabetes Care 22:125-132
36. Lanfredini M, Fiorina P, Peca MG et al. (1998) Fasting and post-methionine load homocysteine values are correlated with microalbuminuria and could contribute to worsening vascular damage in non-insulin dependent diabetes mellitus. Metabolism 27:915-921

37. Agardh CD, Agardh E, Andersson A, Hultberg B (1994) Lack of association between plasma homocysteine levels and microangiopathy in type I diabetes mellitus. Scand J Clin Lab Invest 54:637-641

38. Fonseca VA, Mudaliar S, Schmidt B, Fink LM, Kern PA, Henry RR (1998) Plasma homocysteine concentrations are regulated by acute hyperinsulinemia in non-diabetic but not type 2 diabetic subjects. Metabolism 47:686-689

39. Baliga BS, Reynolds T, Fink LM, Fonseca VA (2000) Hyperhomocysteinemia in type 2 diabetes mellitus: cardiovascular risk factors and effect of treatment with folic acid and pyridoxine. Endocr Pract 6:435-441

40. Mansoor MA, Ueland PM, Svardal AM (1994) Redox status and protein binding of plasma homocysteine and other aminothiols in patients with hyperhomocysteinaemia due to cobalamin deficiency. Am J Clin Nutr 59:631-635

41. Mansoor MA, Bergmark C, Svardal AAM, Lonning PE, Ueland PM (1995) Redox status and protein binding of plasma homocysteine and other aminothiols in patients with early onset peripheral vascular disease. Arterioscler Thromb Vasc Biol 15:232-240 